\title{
A Review Study of The Effect of Air Voids on Asphalt Pavement Life
}

\author{
Ali Mohamed Zaltuom \\ Department of Civil Engineering, College of Engineering, Elmergib University, Libya \\ DOI: https://doi.org/10.21467/proceedings.4.29 \\ * Corresponding author email: amzaltuom@elmergib.edu.ly
}

\begin{abstract}
A BSTRACT
Roadways play a main role in the development of the countries and societies by providing the essential links between the different parts of the country, to facilitate the transport of goods and movement of people. Compaction is one of the most critical factors associated with the performance of asphalt pavements. When the asphalt content is too high, the compact of mixture might too easily, moreover resulting in low air voids. When the asphalt content is too low, the compact of mixture may be stiff and difficult to the specified density. Asphalt pavements are constructed with initial air voids of 6-8\% depending on the type of mixture and pavement layer. Asphalt mixtures has high air voids content during constructed, it is expected to reduce and this densification can be considered as a predominant cause of rutting during initial periods of traffic. Due to air voids reduction, the material becomes stiffer leading to increase rut resistance. Such increase could also be contributed due to age hardening of the material. Inadequate compaction is one of the leading causes of early deterioration and failure of these pavements. The purpose of this paper is to review the importance and the effect of air voids on asphalt pavement lifespan. The result indicated poor compaction of the mix will leave a high percentage of air voids making it susceptible to moisture infiltration and cracking. Conversely, over compaction may cause mixes to have very low air voids making it subject to asphalt bleeding in hot weather environments.
\end{abstract}

Keywords: Asphalt Pavements, Air Voids, Fatigue, Rut Resistance.

\section{Introduction}

Road pavements are one of the largest infrastructure components in most of the developed nations of the world and vitally important to a country's economic development. The construction of a high quality road network directly increases a country's economic output. Roads are constructed to provide fast and safe access between important cities, the construction process will have the added effect of stimulating the construction market [1]. Everything in the life has limited age. For road pavements, wearing surfaces have a life expectancy of between 10-20 years [2]. Asphalt concrete pavements have a short life cycle [3]. Fatigue damage is one of the primary distresses in asphalt concrete pavements besides thermal cracking and rutting [4]. Asphalt consists of four main materials: bitumen, aggregate, fillers

\footnotetext{
(C) 2018 Copyright held by the author(s). Published by AIJR Publisher in Proceedings of First Conference for Engineering
} Sciences and Technology (CEST-2018), September 25-27, 2018, vol. 2.

This is an open access article under Creative Commons Attribution-NonCommercial 4.0 International (CC BY-NC 4.0)

AiR license, which permits any non-commercial use, distribution, adaptation, and reproduction in any medium, as long as the original work is properly cited. ISBN: 978-81-936820-6-7 
A Review Study of The Effect of Air Voids on Asphalt Pavement Life

(fine particles) and air. Asphalt without sufficient air entrapped in the layer will deform under traffic and result in a rutted and rough surface. Field air voids represent the amount of entrapped air in an asphalt layer that has been placed on-site. The objective of asphalt mix design is to achieve an asphalt mix with the lowest practicable air voids without compromising long term performance. Too many air voids and the asphalt becomes permeable to water and air, which causes reduced service life. Too few air voids and the asphalt becomes rutted and deformed under trafficking [5].

Porous asphalt is designed to provide the optimum functional and structural performance particularly the mixture's permeability, modulus and durability. However, these properties are not proportional. High air void content provided in the mixture will improve the permeability but reduces its modulus and durability [6].

\section{Compaction Importance and Pavement Performance}

Construction of high quality roads can help minimize pavement distresses such as rutting, cracking, and other forms of distresses, and improve the long-term performance of the pavement [7]. Compaction is one of the most important factors affecting the performance of asphalt pavements. The asphaltic layer is the most susceptible layer as it is in direct contact with the environment and traffic [8]. The volume of air in a pavement is important because it has a profound effect on long-term pavement performance [9]. Compaction is the process by which the asphalt and aggregate are compressed into a reduced volume. It is generally conceded that the compaction of asphalt concrete is one of the most critical factors associated with the performance of flexible pavements [10].

\subsection{Stability}

Stability can be defined as the resistance to deformation of an asphalt concrete pavement when subjected to traffic loadings under a variety of environmental conditions. A stable pavement maintains its shape and smoothness under repeated loading. In general, the stability increases as density increases with air voids decrease [13]. In this case stability is reduced by five or more points for each percent decrease in air voids [10].

\subsection{Durability}

The durability of asphaltic concrete has been defined as the resistance to weathering and the abrasive action of traffic (These factors can be the result of weather, traffic or a combination of the two). Good durability can be described as the ability to provide long-term performance without premature cracking or ravelling [10] [13]. The durability of asphalt concrete is largely a matter of the durability of the asphalt cement. Reduction in penetration or increase in viscosity with time. Research has shown that for a given asphalt the rate at which an asphalt hardens is related to the total air voids in the asphalt concrete. If the volume and interconnection of voids in a pavement is such that water is transmitted to the base course, the pavement may fail due to loss of strength in the base material [13].

ISBN: 978-81-936820-6-7

Proceedings DOI: 10.21467 /proceedings.4
619

Series: AIJR Proceedings 


\section{$2.3 \quad$ Rutting}

Figure 1 shown that at low air voids (less than $2 \%$ ) the binder almost totally fills the void space between the aggregate particles, so that the mix acts as a fluid and is less resistant to rutting when subjected to heavy traffic. Poorly compacted mixes also have less resistance to rutting due to a weaker structure under traffic.

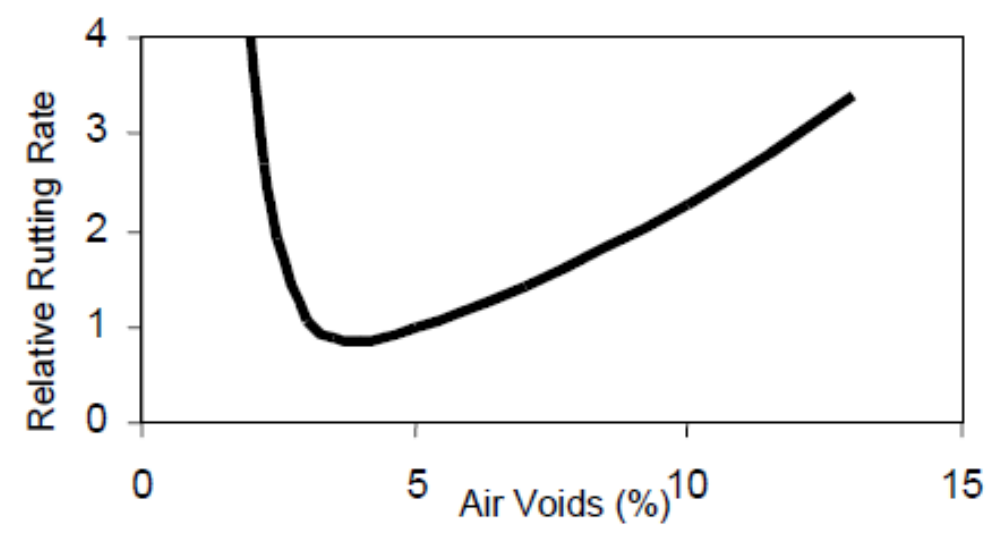

Figure 1: Relative Rutting Rate vs Air Voids

\subsection{Fatigue Life}

The air void content is important on the fatigue behaviour of asphalt concrete. Previous studies results show that high air void contents produce mixes with comparably short fatigue lives. These data suggest that variations in air void content create greater changes in fatigue life [13]. Laboratory investigations indicate that the fatigue life of asphalt concrete could be reduced by 35 percent (or more) for each one percent increase in air voids [10]. Fatigue life or resistance to cracking under repeated load, is directly proportional to the compaction level, Figure 2 shows results of fatigue testing. In this case an increase of air voids from $5 \%$ to $8 \%$ has resulted in a $50 \%$ reduction in fatigue life[15].

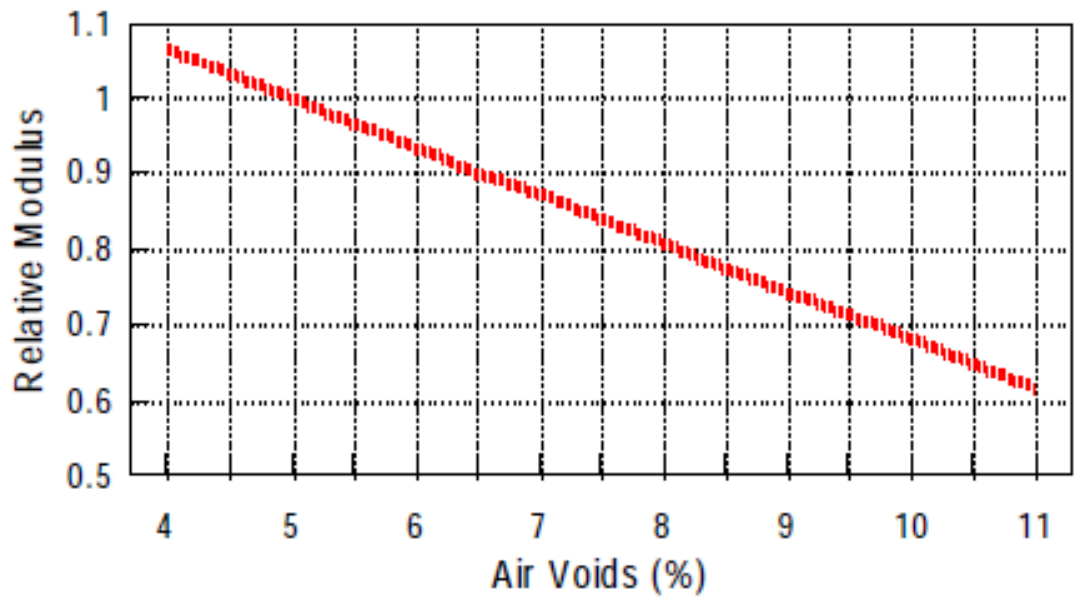

Figure 2: Relative Fatigue Life vs Air Voids

Proceedings of First Conference for Engineering Sciences and Technology (CEST-2018), vol. 2 
A Review Study of The Effect of Air Voids on Asphalt Pavement Life

\subsection{Strength or Stiffness}

Stiffness has been shown to be dependent upon density. The investigators presented the stiffness increases with density suggesting that a more dense mixture results in greater load supporting capabilities of the material [13]. The structural strength of an asphalt mix as measured by its stiffness or modulus, is also related to compaction level. Figure 3 shows strength relative to $5 \%$ air void. In this case an increase in voids from $5 \%$ to $8 \%$ has resulted in a $20 \%$ reduction in stiffness or load carrying capacity [15].

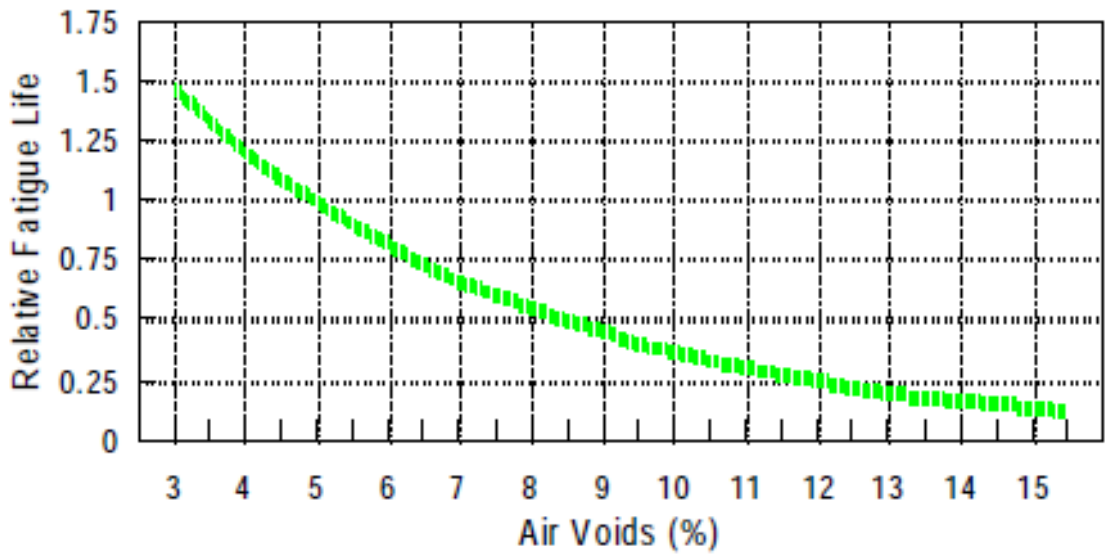

Figure 3: Relative Strength vs. Air Voids

\subsection{Flexibility}

The flexibility of an asphalt paving mixture is defined as the ability of an asphalt pavement to adjust or the ability of the mixture to conform to long-term variations in base and subgrade elevations. In general, those mixtures of acceptable stabilities with high asphalt contents and high air voids will produce mixtures with the greatest flexibility without cracking [13].

Sometimes the need for flexibility conflicts with stability requirements. For example, an opengraded mixture, which is generally more flexible, is designed to be water permeable. A dense graded mix is relatively impermeable, but is less flexible. Both can affect stability.

\section{Factors effecting compaction}

The purpose of compacting asphalt pavements is to density the asphalt concrete and thereby improve its mechanical properties as well as to provide a watertight segment for the underlying materials in the pavement structure [13].

Asphalt compaction is a densification process during which air voids are reduced and compaction in the field is commonly performed using vibratory compactors through the application of combined static and dynamic forces. It is necessary to reduce the air void content of asphalt as the properties of the pavement depends on its density [14].

Impact compaction relies on a high impact force. Most premature failures of asphalt pavement are concerned with poor compaction [12]. 


\section{Design air voids}

Air voids are small airspaces or pockets of air that occur between the coated aggregate particles in the final compacted mix. A certain percentage of air voids is necessary in asphalt mixes to allow for some additional pavement compaction under traffic and to provide spaces into which small amounts of asphalt can flow during this compaction [15]. Air-voids have significant influence on the properties of asphalt pavement, they causes the fatigue damage under repeated load and aggravates the strength of asphalt mixture, causing the macro crack appears in asphalt pavement [16].

Porous asphalt mixture is an open graded gradation that consists of low composition of fine aggregates to allow the mixture to have large quantity of interconnected air voids. These interconnected voids forms capillary channels for the water to flow through and reduce the water runoff from the pavement surface. This shows that the presence of air voids (interconnected and isolated voids) within the mixture is the most significant factor that influences its permeability [17].

Too much air voids also can cause the mixture having excessive aging and stripping problems , that submergence of flexible pavement in moisture over a period of time can damage the fatigue life considerably before design life is achieved [18]. On the other hand, inadequacy of air void within the mixture will lead to the loss in permeability and clogging problem [6].

Least fine materials mixture has caused the mixture to become sensitive towards the changes in voids content as shown by the sudden drop in resilient modulus and large increase in permeability and abrasion loss at high voids content. fine aggregate mixture indicates it is more durable and resilient to deformation but produces low coefficient of permeability. Therefore, any combination of materials (aggregate composition and binder) used should possess strong cohesion and adhesion properties so that a stabilized mixture can be achieved but simultaneously maintaining an open structure of the porous mixture [6].

The range of design air void values in laboratory compacted asphalt mixes is included in asphalt mix design standards. Different types of asphalt include different design air voids as shown in Table 1.

Table 1: Design air voids [9]

\begin{tabular}{|l|l|}
\hline \multirow{2}{*}{ Mix Type } & Marshal Method Mix Design \\
\cline { 2 - 2 } & Air Voids range \% \\
\hline L & $3.8-4.2$ \\
\hline H & $4.9-5.3$ \\
\hline V & $5.9-6.3$ \\
\hline
\end{tabular}

Asphalt with high design air voids $(\mathrm{H})$ is used for locations with heavy traffic volumes where there is potential for further compaction of the asphalt mix after placing. (V) asphalt has higher design air voids and is used for heavily trafficked intersections where there is significant 
A Review Study of The Effect of Air Voids on Asphalt Pavement Life

potential for further compaction of the asphalt mix after placing. As a result of the higher air voids.

Asphalt with lower design air voids ( L) is used for locations with light traffic volumes where there is very little further compaction of the asphalt mix after placing. This type of asphalt achieves high levels of durability and fatigue resistance as a result of the lower air voids and provides long service life. That air void content was the most significant factor affecting on pavement performance [19]. Clearly, the in-place air voids and therefore the in-place density have a significant impact on the pavement life [20].

\section{Importance of Air Voids}

The asphalt should be flexible enough to resist distress. Also, compaction locks the asphaltcoated aggregate particles together to achieve stability and provide resistance to different types of deformation while simultaneously reducing the permeability of the mixture and improving its durability [14].

Previous research has shown that air-voids have significant influence on the strength and durability of asphalt mixture [16]. There is considerable evidence that dense graded mixes should not exceed 8 percent nor fall below 3 percent air voids during their service life. This is because high air void content (above 8 percent) or low air void content (below 3 percent) can cause the following pavement distresses [9].

It was also observed that the frequency of loading inversely affected the fatigue life of the asphalt concrete mixture. In other words as the rate of loading was increased the life of the pavement was decreased [18]. Reducing in density could result in reduced the air voids for asphalt mixture ,therefore could have the opposite effect leads to a loss of fatigue life and serviceability of the pavement [19].

Achieving good density of the hot mix asphalt optimizes all desirable mix properties. The result showed that as the percent of air voids increased the number of load cycles to failure representing fatigue life decreased. Thus fatigue decreases with increasing air voids.

\section{Conclusions}

The quality of compaction is important to the performance of asphalt pavement . Air voids are generally described as the most effective parameter to explain the behavior of the mix. High level of air voids always results in a high expectations of moisture flow within mixtures. Most premature failures of asphalt pavement are concerned with poor compaction. Increase of air voids in asphalt mixture by $1 \%$ than that of design may cause $35 \%$ decrease of pavement fatigue life and double the permeability [12].

Previous study showed that a $1 \%$ increase in air voids (above the base air void level of $7 \%$ ) tends to produce about a $10 \%$ loss in pavement life [21]. The results clearly reflect the importance of air voids when drilling in the AC layer. From the figures we can see that looking at the $4 \%$ central air voids can reduce the gradual response of the material [22]. 


\section{References}

[1] R. Martin, "Highway Engineering," Blackwell Publishing, 2003.

[2] Australian Capital Territory, "Transport Canberra and City Services" Access online on April 2018 at https://www.tccs.act.gov.au/roads-paths/Road_Infrastucture_and_Maintenance/roadpavement.

[3] F. Onyango, Salim R. Wanjala, M. Ndege and L. Masu, "Effect of Rubber Tyre and Plastic Wastes Use in Asphalt Concrete Pavement" International Journal of Civil and Environmental Engineering, vol. 9, no. 11, pp. 1395-1399, sep, 2015. Access online on April 2018 at https://waset.org/publications/10002602/effect-of-rubber-tyre-andplastic-wastes-use-in-asphalt-concrete-pavement.

[4] W.A. Zeiada, K.E. Kaloush, B.S. Underwood and M.S. Mamlouk, "Effect of Air Voids and Asphalt Content on Fatigue Damage Using the Viscoelastic Continuum Damage Analysis," Conference: Airfield and Highway

Pavement, vol. pp. 1122-1133, 2013. Access online on 20 May 2018 at

https://www.researchgate.net/publication/261635455_Effect_of_Air_Voids_and_Asphalt_Content_on_Fatigue_Da mage_Using_the_Viscoelastic_Continuum_Damage_Analysis?enrichId=rgreq-

66454f7fd59a7b9c6301de2f33375701-

XXX\&enrichSource=Y292ZXJQYWd1OzI2MTYzNTQ1NTtBUzozMjU3NjQ1NjMxMjgzMzlAMTQ1NDY3OTc zMjg4Mg\%3D\%3D\&el=1_x_2\&_esc=publicationCoverPdf

[5] A. Papacostas and C. Simpson, "Air voids in asphalt," PAVERTREND, 2016. Access online on MaY 2018 at http://www.pavertrend.com.au/index.php/asphalt/air-voids-in-asphalt?showall=\&limitstart=

[6] Abdul Hassan, M. Mahmud, N. Adi, N. Rahmat, M. Hainin and R. P. Jaya, "Effects of Air Voids Content on The Performance of Porous Asphalt Mixture," Journal of Engineering and Applied Sciences, vol. 11, no. 20, pp. . 1188411887, ARPN. October 2016.

[7] B. A. Chadbourn, E. L. Skok, B.L. Crow, D. E. Newcomb and S. Spindler "The Effect of Voids in Mineral Aggregate (VMA) on Hot-Mix Asphalt pavements," Final report, March, 2000. Minnesota Department of Transportation Office of Research Serices, Ireland, Boulevard.

[8] S. Badeli, A. Carter and G. Doré, "Importance of Asphalt Mixture Air Voids on the Damage Evolution During Freeze-Thaw Cycles," Conference: Canadian Technical Asphalt Association, November, 2016. Access online on March 2018 at

https://www.researchgate.net/publication/308890481_The_Importance_of_Asphalt_Mixture_Air_Voids_on_the_ Damage_Evolution_During_Freeze-Thaw_Cycles

[9] Pavement Interactive, “Compaction Importance," 2012. Access online on March 2018 at http://www.pavementinteractive.org/compaction-importance/

[10] F. N. Finn and J. A. Epps, "Compaction of Hot Mix Asphalt Concrete," Research Report 214-21, Texas Transportation Institute, The Texas A\&M University System College Station, August 1980.

[11] A. Behl, and S. Chandra and, "Compaction Characteristics and Performance of Warm mix Asphalt" 8 th International Conference on maintenance and Rehabilitation of Pavements. July, 2016. Access online on 5 March 2018 at http://rpsonline.com.sg/proceedings/9789811104497/html/037.xml

[12] G. Ying, H. Xiaoming and Y. Wenbin, "The compaction characteristics of hot mixed asphalt mixtures," Journal of Wuhan University of Technology-Mater. Sci. Ed, vol. 29, no. 5, pp. 956-959, GAO. October, 2014. Access online on March 2018 at https://link.springer.com/article/10.1007/s11595-014-1027-z.

[13] J. A. Epps, B. M. Gallaway, W. J. Harper, W. W. Scott and J. W. Seay "Compaction of Asphalt Concrete Pavements," Research Report 90-2F, Texas Transportation Institute, Texas A\&M University College Station, Texas. July 1969.

[14] F. Beainy, S. Commuri and M. Zaman, "Asphalt compaction quality control using Artificial Neural Network," 49th IEEE Conference on Decision and Control, CDC. 2010.

[15] AUSTROADS in conjunction with AAPA, "Pavement Work Tips," no. 17, pp. June, 1999. Access online on April 2018 at http://www.pavementengineering.com.au/wp-content/uploads/2015/12/Pavement-Work-Tips.pdf

[16] H. Jing, L. Pengfei and S. Bernhard "A study on fatigue damage of asphalt mixture under different compaction using 3D-microstructural characteristics," Frontiers of Structural and Civil Engineerring, vol. 11, no. 3, pp. 329-337. September, 2017. Access online on 5 March 2018 at https://link.springer.com/article/10.1007/s11709-017-0407-9

[17] N. Abdul Hassan, M. Z. H. Mahmud, N. Adi, N. Rahmat, M. R. Hainin and R. P. Jaya "Effects of Air Voids Content on the Performance of Porous Asphalt Mixtures," Engineering and Applied Sciences, vol. 11, no. 20, pp. 11884- 
A Review Study of The Effect of Air Voids on Asphalt Pavement Life

11887, ARPN. October, 2016. Access online on 5 March 2018 at
http://www.arpnjournals.org/jeas/research_papers/rp_2016/jeas_1016_5163.pdf

[18] E. A. Igwe and K. I. Amadi-oparaeli “A Proof of Moisture Damage on Fatigue Life of Flexible Pavement Submerged in Water," Journal of Scientific and Engineering Research, vol. 4, no. 9, pp. 210-216, JSERBR. 2017. Access online on 5 March 2018 at http://jsaer.com/download/vol-4-iss-9-2017/JSAER2017-04-09-210-216.pdf

[19] H. Y. Ahmed, "Methodology for Determining Most Suitable Compaction Temperatures for hot Mix Asphalt," Journal of Engineering Sciences, vol. 33, no. 4, pp. 1235-1253. July, 2005. Access online on 5 June 2018 at http://www.aun.edu.eg/journal_files/181_J_9085.pdf

[20] Transportation Research Circular, "Factors Affecting Compaction of Asphalt Pavements," General Issues in Asphalt Technology Committee, Number E-C105.Washington September, 2006. Access online on 5 May 2018 at http://onlinepubs.trb.org/onlinepubs/circulars/ec105.pdf

[21] L. N. Robert,M. P. Joe, and J. C. Newton "Effect of compaction on asphalt concrete performance," Transportation Research Record, no. 1217, pp. 20-28, Abbrev. March, 1990. Access online on March 2018 at http://onlinepubs.trb.org/Onlinepubs/trr/1989/1217/1217-003.pdf

[22] R. Neethu, A. Veeraragavan and J. M. Krishnan "Influence of Air Voids of Hot Mix Asphalt on Rutting Within the Framework of Mechanistic-Empirical Pavement Design," $2^{\text {nd }}$ Conference of Transportation Research Group of India, Procedia - Social and Behavioral Sciences 104, pp. 99-108, 2nd CTRG. 2013. Access online on May 2018 at https://www.sciencedirect.com/science/article/pii/S1877042813044935. 